\title{
Targeted synthesis of porous aromatic frameworks with stimuli-responsive adsorption properties
}

\author{
Rongrong Yuan, Hao Ren*, Hongming He, Lingchang Jiang and Guangshan Zhu*
}

\begin{abstract}
Two porous aromatic frameworks, PAF-36 and PAF-37, containing azo moieties, were synthesized via Sonogashira-Hagihara coupling reactions. Gas sorption measurements indicated that reversible stimuli-responsive adsorption properties were triggered by ultraviolet (UV) irradiation and heat treatment, because of the presence of azo functional groups. The initial Brunauer-Emmett-Teller (BET) surface areas of PAF-36 and PAF-37 were 325 and $443 \mathrm{~m}^{2} \mathrm{~g}^{-1}$, respectively. After UV irradiation, the BET surface areas increased during the trans-cis isomerization process, and the micropore sizes, around 6 and $8 \AA$, also increased. In addition, the $\mathrm{CO}_{2}$ adsorption capacities increased slightly because of trans-cis conversion of azo groups. It is worth mentioning that the $\mathrm{CO}_{2}$ uptakes of the polymers were almost constant during multiple cycles of alternating external stimuli, displaying high switchability of the trans-cis isomerization.
\end{abstract}

\section{INTRODUCTION}

Porous organic frameworks (POFs) constructed purely from light elements via robust covalent bonds (e.g., $\mathrm{B}-\mathrm{O}$, $\mathrm{C}-\mathrm{C}, \mathrm{C}-\mathrm{H}$, and $\mathrm{C}-\mathrm{N}$ ) have properties such as high thermal and chemical stabilities, tunable pore surfaces, and high surface areas. POFs have attracted much attention because of their potential applications in the fields of gas storage and separation, heterogeneous catalysis, and sensors [1-8]. POFs with desired structures and properties can be obtained by designing the initial building blocks. The pore properties of porous materials can be tuned by making specific changes. It has been documented that ion-exchange can successfully control the pore channels. Additionally, porous material properties can be changed by perturbing their functional groups. Light is a convenient stimulus for manipulation, and has been used efficiently to trigger molecular changes. Typical photoresponsive molecules include azobenzene and its derivatives, triphenylmethane leuco derivatives, and spiropyrans [9-11].

Among photoresponsive functional groups, azobenzene and its derivatives have been widely studied because the conditions for inducing changes are easily achieved [12-14]. For azobenzene, the aryl terminal distance of the non-planar cis conformation $\left(d 4-4^{\prime} \approx 6 \AA\right)$ is shorter than that of the planar trans conformation $\left(d 4-4^{\prime} \approx 9 \AA\right)$
$[15,16]$. Azobenzene trans/cis isomerization therefore results in a large change in the geometry, significantly altering the structure of the material. Recently, metal-organic framework skeletons have been successfully decorated with azo moieties, leading to optically responsive gas adsorption behaviors, especially $\mathrm{CO}_{2}$ sorption capacities [17-19]. Zhu and Zhang [20] reported a series of porous organic polymers (POPs) containing azo moieties, and the resulting materials had different $\mathrm{CO}_{2}$ sorption capacities. However, research on optically controlled porous materials still has major challenges [12].

In this study, we designed and synthesized two azobenzene-containing porous aromatic framework (PAF) materials via Sonogashira-Hagihara coupling reactions. The gas sorption properties of the PAF materials were investigated to verify their optically controlled gas-storage properties. The results show that the $\mathrm{N}_{2}$ sorption and $\mathrm{CO}_{2}$ uptake properties are altered by ultraviolet (UV) light irradiation and thermal treatment. The porous properties, including the specific surface area, pore size distribution, and pore volume, were also changed under the stimulus. Furthermore, during multiple cycles of alternating external stimuli, the $\mathrm{CO}_{2}$ uptakes of the polymers were almost constant, indicating the robustness and high switchability of their trans-cis isomerization.

\section{EXPERIMENTAL SECTION}

\begin{abstract}
Materials
Commercially available chemicals were used as received without further purification. $N, N$-dimethylformamide (DMF) and triethylamine $\left(\mathrm{Et}_{3} \mathrm{~N}\right)$ were dried over $\mathrm{CaH}_{2}$ before use. 2,5-dibromoazobenzene, tri(4-ethynylphenyl)amine, and tetrakis ( $p$-bromophenyl)methane were prepared according to the previously reported method [21-23].
\end{abstract}

\section{Synthesis of PAFs}

Synthesis of PAF-36

A mixture of tri(4-ethynylphenyl)amine (160 mg, 0.5

State Key Laboratory of Inorganic Synthesis and Preparative Chemistry, College of Chemistry, Jilin University, Changchun 130012, China * Corresponding authors (emails: zhugs@jlu.edu.cn (Zhu G); renhao@jlu.edu.cn (Ren H)) 
mmol), 2,5-dibromoazobenzene (170 mg, $0.5 \mathrm{mmol}$ ), tetrakis(triphenylphosphine)palladium $(0) \quad(5 \mathrm{mg})$, and copper(I) iodide (3 mg) was added to a round-bottomed flask. After pumping to vacuum, the system volume was tripled with an inert gas $\left(\mathrm{N}_{2}\right)$. Dried DMF $(4 \mathrm{~mL})$ and $\mathrm{Et}_{3} \mathrm{~N}$ $(4 \mathrm{~mL})$ were added through a syringe. The mixture was heated at $80^{\circ} \mathrm{C}$ under a $\mathrm{N}_{2}$ atmosphere for $72 \mathrm{~h}$. After cooling to room temperature, the crude product was obtained by filtration and washed with water, chloroform, methanol, and acetone to remove any unreacted monomers or catalyst residues. Further purification of PAF-36 was carried out by Soxhlet extraction with methanol for $48 \mathrm{~h}$. The product was dried under vacuum for $6 \mathrm{~h}$ at $60^{\circ} \mathrm{C}$ to give PAF-36 (250 mg, 75.8\% yield).

\section{Synthesis of PAF-37}

PAF-37 was synthesized by replacement of tri(4-ethynylphenyl)amine with tetrakis(4-ethynylphenyl)methane (76.7\% yield).

\section{Instruments}

Liquid ${ }^{1} \mathrm{H}$ nuclear magnetic resonance (NMR) spectra were recorded using a Mercury $300 \mathrm{MHz}$ spectrometer. Fourier-transform infrared (FT-IR) spectra (KBr) were recorded using an IFS 66V/S FT-IR spectrometer. Solid-state ${ }^{13} \mathrm{C}$ NMR spectra were obtained using a Bruker Avance III 400 $\mathrm{MHz}$ solid-state NMR spectrometer at a magic-angle-spinning (MAS) rate of $5 \mathrm{kHz}$. Powder X-ray diffraction (PXRD) was performed with a Rigaku D/MAX2550 diffractometer using $\mathrm{Cu} \mathrm{Ka}$ radiation at $40 \mathrm{kV}$ and $200 \mathrm{~mA}$, with a $2 \theta$ range of $4^{\circ}-40^{\circ}$. Scanning electron microscopy (SEM) images were obtained using a JEOL JSM-6700F scanning electron microscope and Iridium (IXRF Systems) software, at an accelerating voltage of $5 \mathrm{kV}$. Transmission electron microscopy (TEM) experiments were performed using a JEOL JEM-3010 microscope, at an accelerating voltage of $300 \mathrm{kV}$. Thermogravimetric analysis (TGA) was performed, using a TGA Q500 thermal analyzer system, up to $800^{\circ} \mathrm{C}$ at a heating rate of $10^{\circ} \mathrm{C} \mathrm{min}^{-1}$ in an air atmosphere. Inductively coupled plasma atomic emission spectroscopy (ICP-AES) was performed using an OPTIMA 3300DV instrument. Elemental analyses $(\mathrm{C}, \mathrm{H}, \mathrm{N})$ were performed using a Perkin-Elmer 240 analyzer. All gas adsorption measurements were performed using a Quantachrome Autosorb iQ2 analyzer, and the pore size distribution curves of the PAF materials were calculated using nonlocal density functional theory (NLDFT). For the cis-trans isomerizations, the degassing port on an a Quantachrome Autosorb iQ2 analyzer was used, with the program set at $150^{\circ} \mathrm{C}$ for $10 \mathrm{~h}$. The UV exposure experiments for the trans-cis isomerizations were performed using a ZF-5 Series 2 UV lamp (6 W; UVP).

\section{RESULTS AND DISCUSSION}

In the synthesis of POF materials with stimuli-responsive adsorption properties, the critical issue is the design and use of suitable building blocks. The easily obtained 2,5-dibromoazobenzene was used as one of the units, and tri(4-ethynylphenyl)amine and tetrakis(4-ethynylphenyl) methane) were selected as suitable nodes. SonogashiraHagihara coupling reactions were used to produce PAF-36 and PAF-37 with azo moieties (Fig. 1).

First, the trans/cis isomerization of 2,5-dibromoazobenzene was confirmed using UV-visible and ${ }^{1} \mathrm{H}$ NMR spectroscopies. A typical strong $\pi \rightarrow \pi^{*}$ absorption band at around $310 \mathrm{~nm}$ and a weak broad $\pi \rightarrow \pi^{*}$ absorption band at around $415 \mathrm{~nm}$ were observed in the UV-visible spectrum of 2,5-dibromoazobenzene in dichloromethane; these are assigned to trans and cis isomerizations, respectively, of the azo functional group. After exposure to UV light, the intensity of the $310 \mathrm{~nm}$ band decreased and the intensity of the $415 \mathrm{~nm}$ band increased slightly, showing that trans-cis isomerization of the azo functional groups occurred (Fig. S1). The ${ }^{1} \mathrm{H}$ NMR spectrum of 2,5-dibromoazobenzene in

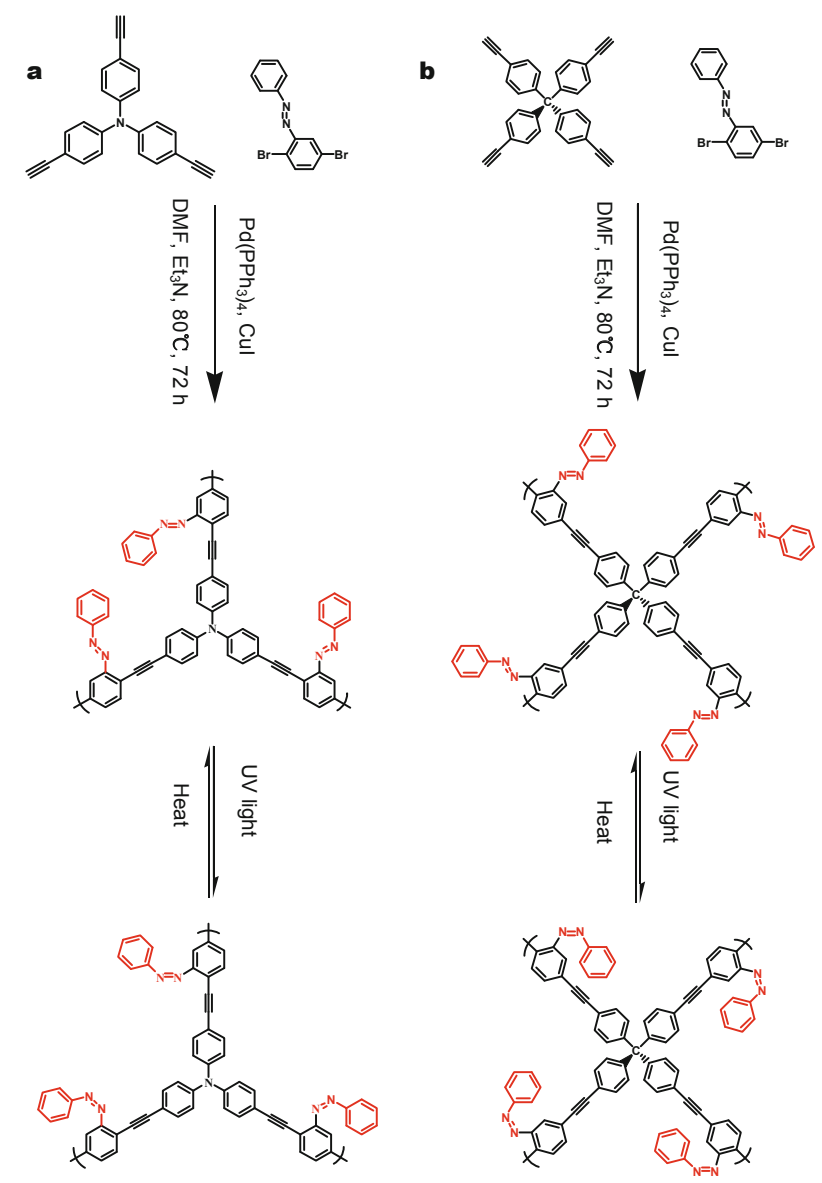

Figure 1 Syntheses and trans/cis isomerizations of PAF-36 (a) and PAF37 (b). 
$\mathrm{CDCl}_{3}$ showed several new peaks after UV irradiation for $5 \mathrm{~h}$, that is ascribed to the formation of cis-2,5-ddibromoazobenzene (Fig. S2). These studies provide good reference information for investigating the objective products.

FT-IR and ${ }^{13} \mathrm{C}$ solid-state NMR spectroscopies, SEM, TEM, TGA, and $\mathrm{N}_{2}$ sorption were used to study the PAF materials and $\mathrm{UV} /$ heat-irradiated samples. $\mathrm{CO}_{2}$ physisorption isotherms of these materials were also measured and repeated three times. The structures of PAF-36 and PAF-37 were initially investigated by FT-IR spectroscopy (Fig. S3). The differences between the FT-IR spectra of the original monomers and final products can be summarized as follows: (1) The disappearance of peaks at around 1075 and $600 \mathrm{~cm}^{-1}$ indicates the disappearance of $\mathrm{C}-\mathrm{Br}$ bonds in the final product. (2) The intense absorption peak associated with the alkynyl C-H stretching vibration near $3300 \mathrm{~cm}^{-1}$ disappears. (3) A low-intensity peak near $2200 \mathrm{~cm}^{-1}$ is observed in the final product, that is ascribed to the presence of alkyne ( $\mathrm{C} \equiv \mathrm{C}-$ ) bonds. (4) The characteristic $\mathrm{N}=\mathrm{N}$ stretching band at around $1480 \mathrm{~cm}^{-1}$ is present in the spectrum of the final product. These observations indicate that the PAF materials have the desired skeletons [24].

${ }^{13} \mathrm{C}$ solid-state NMR cross-polarization (CP)/MAS spectroscopy is a powerful tool for probing the local structures of polymers. As shown in Fig. 2, different types of reso-

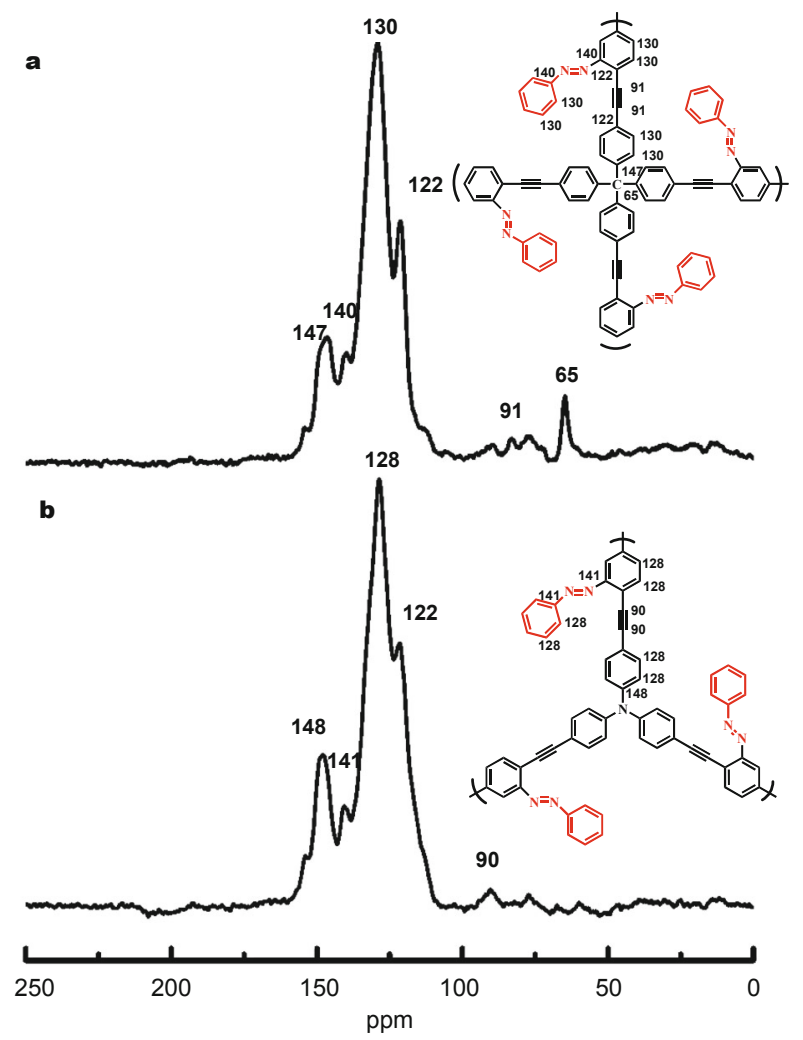

Figure $2{ }^{13} \mathrm{C} \mathrm{CP} / \mathrm{MAS}$ NMR spectra of PAF-36 (a) and PAF-37 (b). nance peaks are observed: (1) a well-resolved peak is detected at $65 \mathrm{ppm}$, associated with the quaternary carbon atom in tetrakis(4-ethynylphenyl)methane (Fig. 2a) [25]; (2) the distinct carbon signals above $120 \mathrm{ppm}$ are assigned to aromatic carbon atoms, indicating the presence of phenyl rings; (3) the peak at around $90 \mathrm{ppm}$ is assigned to the sp carbons in alkyne bonds.

PXRD was used to investigate the crystallinities of PAF36 and PAF-37. The results suggest that the products are amorphous (Fig. S4). The product morphologies were investigated using SEM and high-resolution TEM (Fig. S5). The results show that the products consist of irregular nanoparticles, which easily aggregate, and the pores of the materials are worm-like.

The thermal stabilities of PAF-36 and PAF-37 were investigated using TGA in air (Fig. S6). The approximately $5 \%$ weight loss below $150^{\circ} \mathrm{C}$ corresponds to the removal of guest molecules. A plateau between 150 and $300^{\circ} \mathrm{C}$ was also observed. PAF-36 and PAF-37 decompose above 300 and $350^{\circ} \mathrm{C}$, respectively, showing that they have high thermal stabilities. In addition, when the PAF materials were immersed in common solvents (ethanol, DMF, tetrahydrofuran, and $\mathrm{CHCl}_{3}$ ), no dissolution or decomposition occurred, indicating high chemical stabilities.

ICP-AES was used to detect the metal impurities in the PAFs. Very low concentrations of $\mathrm{Cu}$ and $\mathrm{Pd}$ remained in the PAF networks (Table S1). Elemental analysis results are listed in Table S2, the comparison of experiment $\mathrm{C} / \mathrm{H}(\mathrm{N})$ value and the theoretical $\mathrm{C} / \mathrm{H}(\mathrm{N})$ value indicates the high purities of the materials.

The sample porosities were characterized using $\mathrm{N}_{2}$ sorption isotherms, measured at $77 \mathrm{~K}$. As shown in Figs $3 \mathrm{a}$ and $3 \mathrm{~b}$, the original samples and UV-irradiated samples do not display classical isotherms. There is a sharp gas uptake in the low-pressure region, indicating microporous textures, and a steady increase in gas uptake at high relative pressures [26]. The surface areas of the samples were calculated using the Langmuir and Brunauer-Emmett-Teller (BET) equations; the results are listed in Table 1. It is worth mentioning that after UV-light irradiation for $5 \mathrm{~h}$, the surface areas of the resulting materials were greater than those of the original materials. The pore size distribution curves of the samples, obtained using the NLDFT, showed they had microporous textures. After UV irradiation, the pore sizes, around 6 and $8 \AA$ for PAF-36 and PAF-37, respectively, increased slightly. The pore volumes of PAF-36 and PAF-37 also changed. These results confirm that the introduction of responsive moieties into the porous skeletons can tune the pore properties of PAF materials.

The trans/cis isomerization of azobenzenes leads to significant geometrical and dipole changes. The $\mathrm{CO}_{2}$ adsorption isotherms of PAF- 36 and PAF- 37 at $273 \mathrm{~K}$ show that 

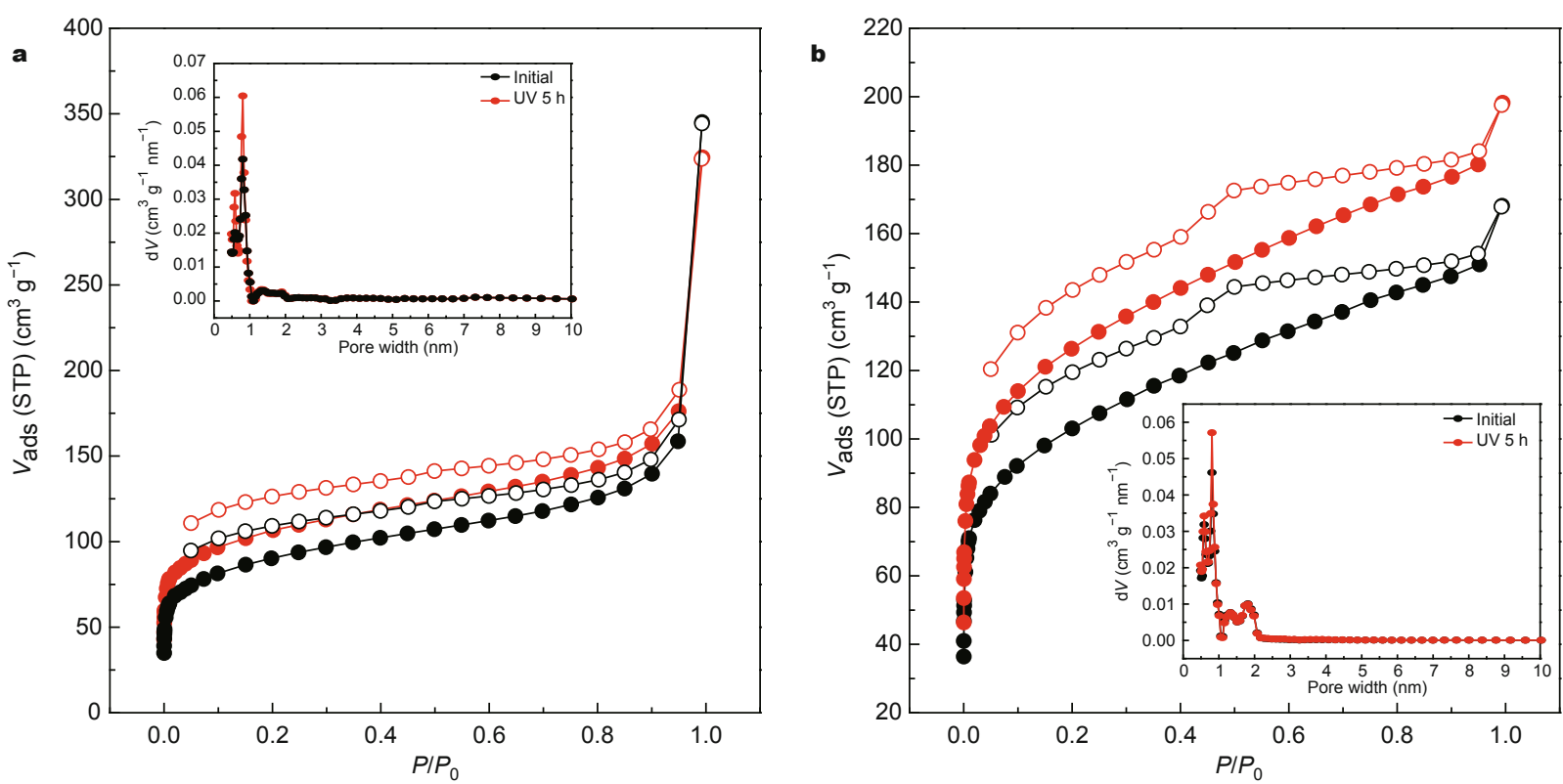

Figure 3 (a) Nitrogen adsorption and desorption isotherms of PAF-36, original (black) and after UV irradiation for 5 h (red); the inset in (a) shows the pore size distribution of PAF-36, initial (black) and after UV irradiation for $5 \mathrm{~h}$ (red). (b) Nitrogen adsorption and desorption isotherms of PAF-37, original (black) and after UV irradiation for $5 \mathrm{~h}$ (red); the inset in (b) shows the pore size distribution of PAF-37, original (black) and after UV irradiation for $5 \mathrm{~h}$ (red).

Table 1 Summary of porosity properties of PAFs at low pressure

\begin{tabular}{|c|c|c|c|c|c|}
\hline PAFs & $S A_{\mathrm{BET}^{\mathrm{a}}}\left(\mathrm{m}^{2} \mathrm{~g}^{-1}\right)$ & $S A_{\text {Langmuir }}{ }^{\mathrm{b}}\left(\mathrm{m}^{2} \mathrm{~g}^{-1}\right)$ & $V_{\text {Total }}{ }^{\mathrm{c}}\left(\mathrm{cm}^{3} \mathrm{~g}^{-1}\right)$ & $\mathrm{CO}_{2}$ uptake $^{\mathrm{d}}\left(\mathrm{cm}^{3} \mathrm{~g}^{-1}\right)$ & $\mathrm{QstCO}_{2}\left(\mathrm{~kJ} \mathrm{~mol}^{-1}\right)$ \\
\hline PAF-36-Initial & 325 & 445 & 0.245 & 28.59 & 27.0 \\
\hline PAF-36-UV & 385 & 500 & 0.273 & 31.18 & 28.4 \\
\hline PAF-37-Initial & 443 & 606 & 0.268 & 26.30 & 36.8 \\
\hline PAF-37-UV & 456 & 641 & 0.279 & 29.62 & 40.7 \\
\hline
\end{tabular}

a) Surface area calculated from the nitrogen adsorption based on the BET model; b) surface area calculated from the nitrogen adsorption isotherms based on the Langmuir model; c) the total pore volume calculated at $P / P_{0}=0.95$; d) the $\mathrm{CO}_{2}$ uptake at $273 \mathrm{~K}, 1$ bar.

the original samples have $\mathrm{CO}_{2}$ adsorption capacities of 28.6 and $26.3 \mathrm{~cm}^{3} \mathrm{~g}^{-1}$ (273 K, 1 bar), respectively. After UV irradiation for $5 \mathrm{~h}$, the $\mathrm{CO}_{2}$ uptakes increased to 31.2 and 29.6 $\mathrm{cm}^{3} \mathrm{~g}^{-1}$ under the same conditions, corresponding to a $9 \%$ and $12 \%$ increase, respectively (Fig. 4). The isosteric heats of adsorption for $\mathrm{CO}_{2}$ uptake were calculated based on the $\mathrm{CO}_{2}$ sorption isotherms of the materials at 273 and $298 \mathrm{~K}$ (Figs S7-S10). The original samples had isosteric heats of adsorption of 27.0 and $36.8 \mathrm{~kJ} \mathrm{~mol}^{-1}$, respectively. After $\mathrm{UV}$ irradiation for $5 \mathrm{~h}$, the isosteric heats of adsorption increased to 28.4 and $40.7 \mathrm{~kJ} \mathrm{~mol}^{-1}$, respectively. These results suggest that cis isomerization of the azo functional groups in the PAFs results in superior $\mathrm{CO}_{2}$ capacity compared with trans isomerization. The results indicate that PAF-37 shows a more obvious $\mathrm{CO}_{2}$ sorption change after $\mathrm{UV}$ irradiation than PAF-36 does, based on the $\mathrm{CO}_{2}$ adsorption values and the heats of adsorption.

To confirm the reversible changes on trans/cis isomerization of azo functional groups in the PAF materials, measurements of the $\mathrm{CO}_{2}$ sorption isotherms of the materials after UV irradiation and thermal regeneration were repeated three times. Figs S9 and $\mathrm{S} 10$ show the detailed $\mathrm{CO}_{2}$ adsorption isotherms of PAF-36 and PAF 37, respectively, and the $\mathrm{CO}_{2}$ adsorption uptakes at 1 bar are listed in Table 2. Almost no decay was observed during trans/cis isomerization after three cycles of alternating external stimuli, indicating that the trans/cis transformation behaviors of the azo functional groups are reversible. These results are in accordance with those for porous organic polymers (UCBZ-1 to 4) containing no azo moieties.

\section{CONCLUSIONS}

In conclusion, two novel PAF materials containing azo groups were successfully synthesized via SonogashiraHagihara cross-coupling reactions. The structures and porosities of the materials were well characterized and discussed. The trans/cis isomerizations of the azo moieties were achieved by UV irradiation and thermal regeneration. Characterization showed that the surface areas of PAF-36 and PAF-37 increased after UV irradiation, and the pore 

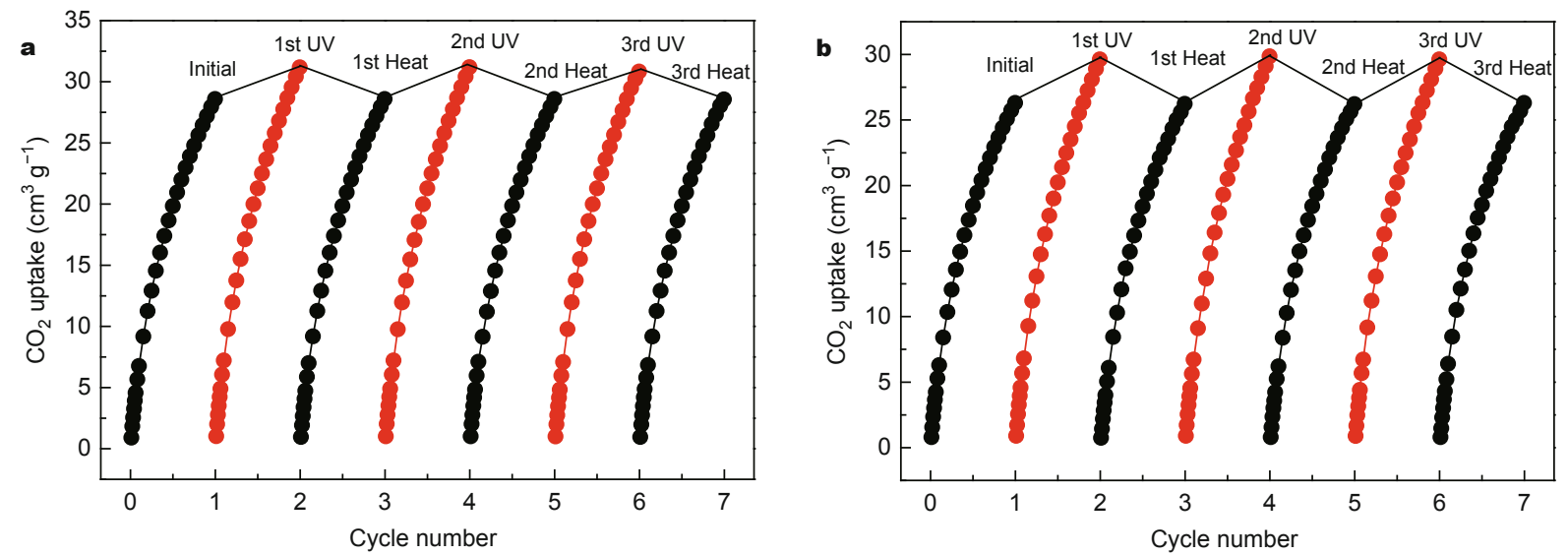

Figure $4 \mathrm{CO}_{2}$ adsorption isotherms of PAF-36 (a) and PAF-37 (b): original samples (black), and samples after UV irradiation (red), and reversibility of PAFs after several cycles of UV and heat treatment.

Table 2 Summary of $\mathrm{CO}_{2}$ adsorption data for materials

\begin{tabular}{cccccccc}
\hline \multirow{2}{*}{ PAFs } & \multicolumn{5}{c}{$\mathrm{CO}_{2}$ uptake $\left(\mathrm{cm}^{3} \mathrm{~g}^{-1}\right), 273 \mathrm{~K}, 1$ bar } \\
\cline { 2 - 7 } & Initial & 1st-UV & 1st-Heat & 2nd-UV & 2nd-Heat & 3rd-UV & 3rd-Heat \\
\hline PAF-36 & 28.59 & 31.18 & 28.58 & 31.19 & 28.59 & 28.83 & 26.55 \\
PAF-37 & 26.30 & 29.62 & 26.23 & 29.86 & 29.43 & 26.29 \\
\hline
\end{tabular}

sizes also changed slightly, indicating that the introduction of responsive moieties into their porous skeletons could be used to tune the pore properties of POF materials. Furthermore, measurements of the $\mathrm{CO}_{2}$ adsorption isotherms of PAF-36 and PAF-37 after UV irradiation and thermal regeneration were repeated three times. The $\mathrm{CO}_{2}$ uptakes by PAF-36 and PAF-37 increased by $9 \%$ and $12 \%$, respectively, after UV irradiation, and almost regained their initial values after thermal regeneration, indicating the reversibility of the photoresponsive behaviors of the materials. These two novel porous polymers with stimuli-responsive adsorption properties have a range of potential applications, and are worth further study.

\section{Received 1 December 2014; accepted 8 January 2015;} published online 22 January 2015

1 Ding SY, Wang W. Covalent organic frameworks (COFs): from design to applications. Chem Soc Rev, 2013, 42: 548-568

2 Dawson R, Cooper AI, Adams DJ. Nanoporous organic polymer networks. Prog Polym Sci, 2012, 37: 530-563

$3 \mathrm{Xu} \mathrm{YH}$, Jin SB, Xu H, et al. Conjugated microporous polymers: design, synthesis and application. Chem Soc Rev, 2013, 42: 8012-8031

4 Zou XQ, Ren H, Zhu GS. Topology-directed design of porous organic frameworks and their advanced applications. Chem Commun, 2013, 49: 3925-3936

5 Kundu DS, Schmidt J, Bleschke C, et al. A microporous binol-derived phosphoric acid. Angew Chem Int Ed, 2012, 51: 5456-5459

6 Ben T, Ren H, Ma SQ, et al. Targeted synthesis of a porous aromatic framework with high stability and exceptionally high surface area. Angew Chem Int Ed, 2009, 48: 9457-9460

7 Li BY, Zhang YM, Ma DX, et al. Mercury nano-trap for highly effective and highly efficient removal of mercury(II) from aqueous solution. Nat Commun, 2014, 5: 5537-5544
8 Li BY, Zhang YM, Krishna R, et al. Introduction of $\pi$-complexation into porous aromatic framework for highly selective adsorption of ethylene over ethane. J Am Chem Soc, 2014, 136: 8654-8660

9 Bandara HMD, Burdette SC. Photoisomerization in different classes of azobenzene. Chem Soc Rev, 2012, 41: 1809-1825

10 Berkovic G, Krongauz V, Weiss V. Spiropyrans and spirooxazines for memories and switches. Chem Rev, 2000, 100: 1741-1753

11 Minkin V. Photo-, thermo-, solvato-, and electrochromic spiroheterocyclic compounds. Chem Rev, 2004, 104: 2751-2776

12 Mukhopadhyay RD, Praveen VK, Ajayaghosh A. Photoresponsive metal-organic materials: exploiting the azobenzene switch. Mater Horiz, 2014, 1: 572-576

13 Yagai S, Kitamura A. Recent advances in photoresponsive supramolecular self-assemblies. Chem Soc Rev, 2008, 37: 1520-1529

14 Russew MM, Hecht S. Photoswitches: from molecules to materials. Adv Mater, 2010, 22: 3348-3360

15 Borisenko V, Burns DC, Zhang ZH, et al. Optical switching of ion-dipole interactions in a gramicidin channel analogue. J Am Chem Soc, 2000, 122: 6364-6370

16 Liu NG, Chen Z, Dunphy DR, et al. Photoresponsive nanocomposite formed by self-assembly of an azobenzene-modified silane. Angew Chem Int Ed, 2003, 42: 1731-1734

17 Lyndon R, Konstas K, Ladewig BP, et al. Dynamic photo-switching in metal-organic frameworks as a route to low-energy carbon dioxide capture and release. Angew Chem Int Ed, 2013, 52: 3695-3698

18 Park J, Yuan DQ, Pham KT, et al. Reversible alteration of $\mathrm{CO}_{2}$ adsorption upon photochemical or thermal treatment in a metal-organic framework. J Am Chem Soc, 2012, 134: 99-102

19 Yanai N, Uemura T, Inoue M, et al. Guest-to-host transmission of structural changes for stimul-responsive adsorption property. J Am Chem Soc, 2012, 134: 4501-4504

20 Zhu YL, Zhang W. Reversible tuning of pore size and $\mathrm{CO}_{2}$ adsorption in azo functionalized porous organic polymers. Chem Sci, 2014, 5: 4957-4961

21 Anwar N, Willms T, Grimme B, et al. Light-switchable and monodisperse conjugated polymer particles. ACS Macro Lett, 2013, 2: 766-769 
22 Jiang JX, Trewin A, Su FB. Microporous poly(tri(4-ethynylphenyl) amine) networks: synthesis, properties, and atomistic simulation. Macromolecules, 2009, 42: 2658-2666

23 Lu W, Yuan D, Zhao D, et al. Porous polymer networks: synthesis, porosity, and applications in gas storage/separation. Chem Mater, 2010, 22: 5964-5972

24 Yuan RR, Ren H, Yan ZJ, et al. Robust tri(4-ethynylphenyl)aminebased porous aromatic frameworks for carbon dioxide capture. Polym Chem, 2014, 5: 2266-2272

25 Stöckel E, Wu XF, Trewin A, et al. High surface area amorphous microporous poly(aryleneethynylene) networks using tetrahedral carbon- and silicon-centred monomers. Chem Commun, 2009, $212-214$

26 Sing K, Everett D, Haul R, et al. Reporting physisorption data for gas/solid systems with special reference to the determination of surface area and porosity. Pure Appl Chem, 1985, 57: 603-619
Acknowledgements This work was supported by the National Basic Research Program of China (2012CB821700 and 2014CB931804), and the Major International (Regional) Joint Research Project of the National Natural Science Foundation of China (21120102034).

Author contributions Yuan R and Zhu G designed and engineered the samples; Yuan R wrote the manuscript with support from Ren H; Jiang $\mathrm{L}$ performed the gas adsorption experiments and collected the data; $\mathrm{He}$ $\mathrm{H}$ and Ren $\mathrm{H}$ contributed to the data analysis and theoretical analysis. All authors contributed to the general discussion.

Conflict of interest The authors declare that they have no conflict of interest.

Supplementary information Supporting data are available in the online version of the paper.
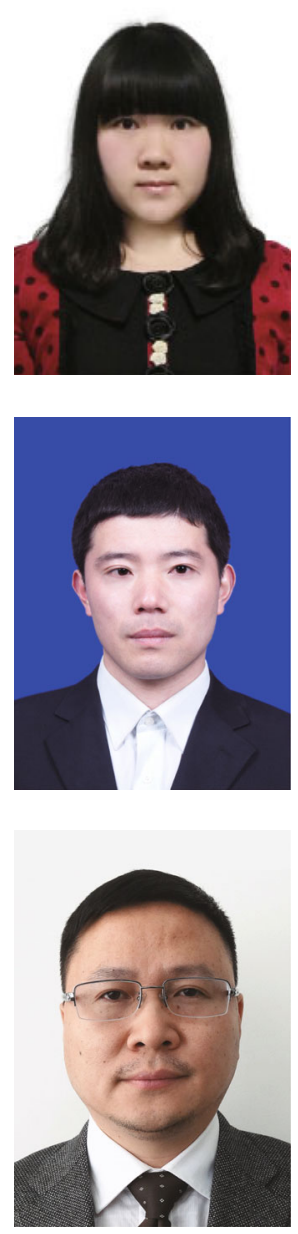

Rongrong Yuan obtained her bachelor's degree in chemistry from Tsingdao University of Science and Technology in 2011. She then joined Professor Guangshan Zhu's research group for her master and PhD studies, mainly working on targeted synthesis of porous aromatic frameworks for gas storage. Her research interests focus on the synthesis, structure, and functions of porous organic frameworks.

中文摘要 本文通过Sonogashira-Hagihara反应制备了两种骨架含有偶氮官能团的多孔芳香骨架材料, PAF-36和PAF-37, 并研究了它 们的氮气及二氧化碳吸附性能. 偶氮官能团经过紫外光照射和加热可以实现顺式和反式结构变换. 它们初始BET比表面积分别是 325 $\mathrm{m}^{2} \mathrm{~g}^{-1}$ 和 $443 \mathrm{~m}^{2} \mathrm{~g}^{-1}$. 经过紫外光照, 偶氮官能团发生顺反异构化, 材料的BET比表面积以及在 $6 \AA$ 和 $8 \AA$ 的孔径分布均有所增大. 另外, 紫 外光照后, 材料的 $\mathrm{CO}_{2}$ 吸附性能也有一定提高. 对样品进行了三次紫外/加热循环实验后, 样品 $\mathrm{CO}_{2}$ 吸附量几乎保持不变, 表明材料中可 以发生顺反异构化的偶氮基团具有高效的开关性能. 在多孔材料中引入光控基团, 可以有效改变材料的孔结构, 进而影响材料的气体 分子吸附性能.

Guangshan Zhu received his BSc and PhD degrees in chemistry from Jilin University (China) in 1993 and 1998 , respectively. He was then appointed as an assistant professor at the Department of Chemistry (Jilin University). From 1999 to 2000, he worked as a post-doctoral research associate at Tohoku University in Japan. He has been a full professor of Jilin University since 2001. The current research in his group focuses on the design and synthesis of zeolites, metal-organic frameworks, and porous organic frameworks for applications in gas-liquid adsorption, separation, and other advanced applications.

Hao Ren obtained his bachelor's degree in chemistry from Jilin University in 2006. He then joined Professor Guangshan Zhu's research group for his master and $\mathrm{PhD}$ studies, mainly working on targeted synthesis of porous aromatic frameChemistry, Jilin University. His research interests focus on the synthesis, structure, and functions of porous organic frameworks. 